\title{
O processo de implantação do PROEJA na cultura escolar da educação profissional ${ }^{1}$
}

\author{
The process of PROEJA'S implementation in the school culture of professional \\ education \\ Proceso de implantación de PROEJA en la cultura escolar de la educación \\ profesional
}

\section{VALDINEI MARCOLLA}

\begin{abstract}
Resumo: Este artigo analisa a implantação da proposta pedagógica do PROEJA em um Instituto Federal, considerando a integração curricular, a construção do currículo integrado na prática pedagógica e as relações com a cultura escolar. Em uma pesquisa qualitativa inseriu-se na realidade da Instituição e do Curso, mediante coleta de documentos, observações diretas em reuniões e aulas, e entrevistas semiestruturadas com professores e alunos do curso. Os resultados explicitaram embates presentes na implementação do programa para o efetivo reconhecimento do PROEJA pela cultura escolar.
\end{abstract}

Palavras-chave: política educacional; implementação do PROEJA; cultura escolar.

Abstract: This paper analyzes the implementation of the pedagogical proposal PROEJA at a Federal Institute, taking in consideration curricular integration, the construction of the integrated curriculum in pedagogical practice and its relationship with the school culture. As a qualitative research, there was immersion in the reality of the Course and Institution through the gathering of documents, direct observation in meetings and classes, and semi-structured interviews with teachers and students. The results showed the present conflicts in the implementation of the program for the effective recognition PROEJA by the school culture.

Keywords: educational policy; implementation of PROEJA; school culture.

Resumen: Este artículo analiza la implantación de la propuesta de PROEJA en el Instituto Federal, considerando la integración curricular, la construcción de un currículo integrado en la práctica pedagógica y las relaciones con la cultura escolar. En una investigación cualitativa se insirió en la realidad de la Institución

1 Versão revisada de trabalho apresentado na 35a. Reunião Anual da Associação Nacional de PósGraduação e Pesquisa em Educação (Anped), realizado no período de 21 e 24 de outubro de 2012, na cidade de Porto de Galinhas, Pernambuco. 
y del curso, mediante recogido de documentos, observaciones directas en reuniones y clases, y entrevistas semiestructuradas con profesores y alumnos del curso. Los resultados explicitaron embates presentes en la implementación del programa para el efectivo reconocimiento de PROEJA por la cultura escolar.

Palabras clave: política educativa; implementación de PROEJA; cultura escolar.

\section{INTRODUÇÃO}

Este texto tem como objetivo apresentar algumas considerações acerca do processo de implantação do Programa Nacional de Integração da Educação Profissional com a Educação Básica na Modalidade de Educação de Jovens e Adultos (PROEJA), no campus Pelotas do Instituto Federal de Educação, Ciência e Tecnologia Sul-rio-grandense (IFSul).

A pesquisa que originou este trabalho procurou investigar aspectos ligados à constituição do curso, à proposta pedagógica e aos processos pedagógicos. Tendo em vista a quantidade de dados coletados - entrevistas e observações de práticas docentes ${ }^{2}-$, pretende-se apresentar um recorte da pesquisa, procurando destacar alguns aspectos relativos à implementação do curso, à integração curricular entre as áreas de conhecimento e aos reflexos da cultura escolar nesse processo.

\section{A ESCOLA E SUA CULTURA}

Nas últimas duas décadas do século XX, cresceu entre os pesquisadores a compreensão de que as instituições escolares precisam ser estudadas no seu tempo e espaço de atuação, "Pois expressam um lento processo de construção social e cultural, no qual influem tanto as necessidades e interesses da sociedade, quanto ações, significados, desejos, experiências coletivas e individuais daqueles que passam pelas escolas" (MAFRA, 2003, p. 124). Não obstante, a escola está em constante processo de ressignificação, que independe do cumprimento de suas funções e deliberações sociais, visto que esse movimento é produto da constituição histórica da instituição e das pessoas que a compõem. Segundo Mafra,

Se as instituições escolares cumprem, por um lado, funções sociais determinadas, elas igualmente se modificam independentemente dessas determinações, pois são moldadas e construídas pela história sociocultural e profissional de seus personagens, de suas vivências, de suas realizações, de seus sonhos e de suas possibilidades (Idem, p. 124-125).

2 Por questões éticas todos os sujeitos da pesquisa assinaram o termo de consentimento livre e esclarecido e os nomes utilizados para distingui-los são fictícios. 
Para Nóvoa (1995) e Teixeira (2003), a escola é compreendida como uma organização social constituída de grupos reais e relacionais, inserida em uma comunidade local, com identidade e cultura próprias e com espaço de autonomia para se construir, desconstruir-se e se descobrir, na concretização de um projeto educativo próprio.

As diferenças existentes entre as instituições escolares, que por um longo período foram renegadas à clandestinidade ou desconsideradas, ganham destaque na atualidade e passam a ser consideradas potencialidades na busca da qualificação das atividades educativas. Nóvoa (1995) afirma que vem se consolidando uma visão em que "as instituições escolares adquirem uma dimensão própria, enquanto espaço organizacional onde também se tomam importantes decisões educativas, curriculares e pedagógicas" (1995, p. 15). Dessa forma, a escola é espaço de produção de saberes com uma cultura própria, a qual é resultado das relações e ações dos atores que a compõem e se revertem em uma identidade da instituição.

Segundo Nóvoa (1995), Tyack e Cuban (2001), Viñao Frago (2001, 2006) e Teixeira (2003), o fato de haver na escola uma cultura própria e predominante não significa a inexistência de conflitos entre os que compõem a instituição. Em suma, o que acontece no dia a dia escolar são relações de poder entre grupos distintos, que definem rumos e encaminhamentos que a escola adota. A partir dessa percepção é importante considerar que havendo os grupos e os "Subgrupos específicos dentro da instituição [estes] não autorizam uma crença na cultura como valor integrador e uniformizante do agir e do pensar." (TEIXEIRA, 2003, p. 180). Essas relações e interesses distintos estabelecidos no interior das escolas, aliadas aos aspectos formais, dão corpo à estrutura e à organização escolar.

No entender de Teixeira (2003), a cultura escolar tem a função de solucionar os problemas fundamentais do seu grupo, garantindo sua sobrevivência e adaptação às interferências externas e à integração de seus processos internos, no intuito de solidificar a estrutura escolar. A autora enfatiza, ainda, que a cultura da escola é resultado de uma dinâmica histórica, que não nasce no trabalho individual de cada professor em sala de aula; mas nas relações travadas entre os sujeitos (professores, alunos, gestores, demais funcionários e pais) no interior da instituição de todos com o exterior dela. Portanto, "Ela constitui uma variável dependente das condições que entram em jogo na organização e funcionamento internos da escola, e é influenciada pelo seu contexto social, econômico, político e cultural" (TEIXEIRA, 2003, p. 179).

Teixeira (2003) e Viñao Frago (2006) afirmam que existe na escola uma organização informal - produzida a partir dos sujeitos escolares (professores, funcionários, pais e alunos) - que é reflexo de relações e práticas culturais dos indivíduos e suas subjetividades. Essa forma de organização, própria de cada 
escola, tende a refletir-se no assentimento ou resistência ante as propostas de inovação, nos modos de trabalhar com os alunos, nas maneiras de enfrentamento de problemas de disciplina, na aceitação ou não de mudanças na rotina de trabalho, etc.

Nessa perspectiva, o cotidiano de uma instituição escolar, sua comunidade intraescolar (docentes, funcionários, alunos, etc.) e extraescolar (familiares e comunidade que compõem o entorno da escola), produzem ritmos e significados que estabelecem as particularidades da escola como um todo. Assim, a organização e o funcionamento da escola como instituição tende a ser produto de múltiplas relações entre a estrutura formal e a estrutura constituída a partir das relações estabelecidas entre os atores escolares, com os respectivos interesses e posições diversas, em movimentos e complexidades que concebem uma cultura própria a cada escola.

Embora haja uma cultura própria, é preciso levar em consideração que a escola não é um espaço isolado da sociedade, uma vez que sua cultura está, muitas vezes, adaptada a concepções pretéritas, que tendem a resistir aos processos de transformação vividos na macro realidade, mesmo que esses possam ser considerados movimentos com poder esmagador.

Em virtude disso, qualquer movimento produzido no exterior da escola tende a chocar-se ou a ser aceita pelas bases culturais de resistência ou de aceitação formadas nesse ambiente. Em tal caso, há movimentos que articulam a autonomia do trabalho docente com o poder que ele tem no espaço da sala de aula, o qual, somado à cultura da instituição, pode resultar em movimentos de oposição às situações, normas ou projetos escolares, ou de sua aceitação. Por consequência, quaisquer propostas advindas do exterior que tentem romper com o estabelecido na realidade da escola ou da sala de aula, exigem tempo e diálogo entre os professores e gestores escolares, vindo a requerer entendimentos, diálogos e compartilhamento de posições e projetos que ajudem na superação de práticas e modelos pedagógicos até então presentes nos processos escolares.

Assim, as distinções são produto dos contextos escolares (escola de Ensino Fundamental ou de Ensino Médio), das organizações internas de gestão e ensino, das estruturas acadêmicas e curriculares das escolas, dos atores (suas práticas, mentalidades, etc.) e da forma como eles se relacionam entre si. O contexto escolar evidencia a cultura dos professores, dos gestores, dos funcionários (modos de fazer e de pensar transmitidos entre as gerações), dos alunos, das famílias e da comunidade, assim como suas expectativas, interesses, mentalidades e modos de proceder. 
Outro aspecto salientado por Viñao Frago $(2001,2006)$ diz respeito aos limites da cultura escolar e à tenuidade que há entre a continuidade histórica e o câmbio, as tradições e as inovações na realidade escolar, pois, para ele, "As culturas escolares também mudam: não são eternas. Constituem uma combinação - entre outras muitas possíveis - de tradição e mudança” (2001, p. 33) ${ }^{3}$, pois não se pode desconsiderar as transformações que acontecem intramuros e extramuros escolares, tendo em vista que esses movimentos de mudança, em longo e médio prazo, tendem a alterar a cultura escolar. Indubitavelmente, as mudanças com processos inovadores se iniciam no cotidiano da escola ou mesmo fora dele e podem ser resultado de êxitos ou fracassos das reformas educativas (produto do contexto social e político, do apoio ou resistência, das contradições internas, do financiamento, etc.), e de seus efeitos e influências na cultura escolar e vice-versa.

\section{PROGRAMA DE EDUCAÇÃO PROFISSIONAL PARA JOVENS E ADULTOS}

Por meio do Decreto n 5.478/05 (BRASIL, 2005), o Governo Federal estabeleceu, no âmbito dos centros de educação tecnológica, escolas técnicas, escolas agrotécnicas e escolas técnicas vinculadas às universidades federais (atualmente, em sua maioria instituições federais de educação tecnológica), o Programa de Integração de Educação Profissional ao Ensino Médio na Modalidade de Educação de Jovens e Adultos (PROEJA). O mesmo decreto "Expôs a decisão governamental de atender à demanda de jovens e adultos pela oferta de educação profissional técnica de nível médio" (BRASIL, 2007, p. 12).

O Decreto estabelecia a oferta de educação de jovens e adultos com qualificação profissional na rede federal, indicando a obrigatoriedade da oferta de $10 \%$ das vagas de cada unidade escolar para cursos nessa modalidade. A forma impositiva do documento legal gerou críticas por parte de gestores e professores das instituições, que ressaltavam sua ilegalidade, tendo em vista que, ao estabelecer esse parâmetro, o mesmo feria a autonomia administrativa, patrimonial, financeira, didático-pedagógica e disciplinar das instituições federais de educação tecnológica. Aliado a isso, desconsiderava as condições pedagógicas para ministrar cursos no formato proposto (educação profissional integrada à educação básica na modalidade EJA), uma vez que, após a reforma na educação profissional do Decreto 2.208/97, de 17 de abril de 1997, as instituições federais reduziram significativamente o quadro de docentes do Ensino Médio. Por

3 Las culturas escolares también cambian: no son eternas. Constituyen una combinación - entre otras muchas posibles - de tradición y cambio, no original - (tradução nossa). 
consequência, não havia na rede um corpo de professores formados para atuar no campo específico da educação de jovens e adultos, no Ensino Médio e no Ensino Médio integrado à educação profissional (ALVES; CASTRO, 2007).

Com intuito de responder às demandas de aplicação do Programa e de formação de jovens e adultos de forma integrada (educação básica e profissional), o Governo Federal promulga o Decreto n 5.840 , de 13 de julho de 2006, em substituição ao Decreto n ${ }^{\circ} 5.478 / 05$, estabelecendo alterações no programa, no que se refere a "Ampliação da abrangência, no que concerne ao nível de ensino, pela inclusão do ensino fundamental [...] e a admissão dos sistemas de ensino estaduais e municipais e entidades privadas nacionais de serviço social". Além disso, o documento altera sua denominação, que passa a ser chamado de Programa Nacional de Integração da Educação Profissional com a Educação Básica na Modalidade de Educação de Jovens e Adultos (BRASIL, 2007, p. 12).

O novo texto, no segundo parágrafo, do seu primeiro Artigo, fixa que os “cursos e programas do PROEJA deverão considerar as características dos jovens e adultos atendidos" podendo estar articulados (inciso I) "Ao ensino fundamental ou ao Ensino Médio, objetivando a elevação do nível de escolaridade do trabalhador" e (inciso II) "Ao Ensino Médio, de forma integrada ou concomitante" (BRASIL, 2007, p. 68). Também, estabelece que os cursos deverão pautar-se nas diretrizes curriculares nacionais e nos atos normativos do Conselho Nacional de Educação para a Educação Profissional Técnica de Nível Médio, para o Ensino Fundamental, para o Ensino Médio e para a Educação de Jovens e Adultos.

No tocante à formação dos alunos, o Documento Base traz o entendimento de que o Programa objetivará garantir a reinserção, no sistema educacional, de jovens e adultos que não concluíram ou não tiveram acesso às redes escolares de Educação Básica e profissionalizante em sua faixa etária regular. Entende-se que essa formação será voltada para a vida e não exclusivamente para o mercado de trabalho, enquanto uma

Formação humana, no seu sentido lato, com acesso ao universo de saberes e conhecimentos científicos e tecnológicos produzidos historicamente pela humanidade, integrada a uma formação profissional que permita compreender o mundo, compreender-se no mundo e nele atuar na busca de melhoria das próprias condições de vida e da construção de uma sociedade socialmente justa. (BRASIL, 2007, p. 13).

Com essa perspectiva de formação, o programa estrutura-se de maneira a integrar a educação profissional com a Educação Básica (Ensino Médio) na modalidade Educação de Jovens e Adultos (EJA), prevendo as possibilidades 
de articulação entre o Ensino Médio e a Educação Profissional nas formas integradas, em que a formação integra a cultura geral e profissionalizante e, concomitantemente, na qual ambas as formações ocorrem de forma paralela.

\section{EXPERIÊNCIA DE IMPLEMENTAÇÃO DO PROEJA}

O curso de Manutenção e Suporte em Informática - PROEJA - inicia as atividades em 2007, mas, para se entender seu processo de constituição, é preciso voltar ao ano de 1998 e compreender a gestação e o andamento do Projeto Especial de Ensino Médio para Adultos (EMA), no então Centro Federal de Educação Tecnológica de Pelotas (CEFET/RS).

No ano de 1998, a Direção-Geral da Instituição convidou um grupo de professores/coordenadores para pensar uma proposta de curso com o foco no público jovem e adulto. $\mathrm{Na}$ época, segundo os professores, o grupo se comprometeu com a construção do projeto, mas, em contrapartida, exigiu autonomia para elaborar um projeto com base numa proposta de ensino diferenciada, que estivesse focado na realidade local, nos saberes e nas vivências dos discentes e em uma concepção transdisciplinar.

Ainda, conforme os depoimentos, o grupo que se disponibilizou a conduzir a elaboração do projeto e, posteriormente, trabalhou no Curso, centrouse nas interlocuções entre as áreas do conhecimento, não se preocupando com a elaboração de listas de conteúdos ou com a distribuição da carga-horária das disciplinas que comporiam a grade curricular. Dessa maneira, durante a construção da proposta, a ideia central foi estabelecer o diálogo entre as áreas de conhecimento e, com isso, constituir uma aproximação entre elas. $\mathrm{Na}$ prática, ou durante o andamento do Curso, esse trabalho converteu-se em uma ação transdisciplinar, que acontecia por meio de projetos de ensino, em que os conteúdos eram trabalhados pelos professores de forma articulada e, quando possível, em grandes aulas, que envolviam parte do grupo docente do curso.

Em 1999, foi ofertada a primeira turma do EMA, com o intuito de possibilitar o Ensino Médio, para trabalhadores ou não, que estivessem afastados da escola e não houvessem conseguido concluir a educação básica durante a faixa etária considerada regular. O EMA procurava garantir aos alunos adultos a volta aos bancos escolares, para que dessem sequência aos estudos, podendo concluir a escolarização básica e, em alguns casos, ocupar outros espaços no mercado de trabalho ou retornar a esse mercado. O Projeto objetivava, ainda, 
Assegurar a jovens e adultos trabalhadores, excluídos do Sistema Formal de Educação, uma oportunidade educacional de Ensino Médio e desenvolver uma experiência pedagógica, tendo como base uma concepção de educação, que forme um cidadão crítico, autônomo e com capacidade de ação social (CEFET, 1999, p. 4).

Em virtude disso, o Projeto foi alicerçado na ideia de resgatar a cidadania do trabalhador, considerando o saber produzido pelos alunos/trabalhadores por meio dos fazeres ou das suas ações no cotidiano. Nessa perspectiva, o ensino deveria valorizar os saberes dos indivíduos e dar a eles o direito de construir seus próprios conhecimentos que, no contexto escolar, precisariam ser conectados aos conceitos e significados científicos, para que os alunos pudessem estabelecer uma relação entre os saberes do fazer e os conhecimentos científicos (CEFET, 2004).

No projeto pedagógico do EMA, é possível perceber que o primordial na proposta era o resgate e a valorização do saber construído pelos alunos/ trabalhadores, por se entender que esse saber seria ferramenta principal no trabalho pedagógico do professor. Dessa forma, os conteúdos trabalhados no EMA deveriam ser desenvolvidos e constantemente contextualizados a partir da vivência e da prática de cada um dos alunos/trabalhadores (CEFET, 1999).

O Projeto Especial de Ensino Médio para Adultos constituía-se, nessa concepção, a partir da realidade do aluno, o qual era instigado, por meio de experimentação, pesquisa, trabalho em grupo, discussões e reflexões a analisar a sua realidade, com base em que, construía o seu conhecimento (CEFET, 2004).

Ao falar sobre o Projeto, o professor Gustavo, faz referência à resistência que enfrentou dentro da Instituição e descreve alguns detalhes das práticas desenvolvidas na realidade do EMA. No depoimento, ele afirma, que:

A gente encontrou uma série de restrições [quando da implantação do EMA], nos chamavam de "supletivozinho", mas foi uma experiência fantástica, desde o layout da sala de aula [em "L"] que não era aquelas classes enfileiradas... até tu veres pessoas com mais de vinte anos afastados dos bancos escolares e quando chegaram ao final do ano "estavam" escrevendo, interpretando e conseguindo fazer uma síntese... Então foi uma experiência maravilhosa e a gente trabalhava exatamente com "trabalhadores chão de fábrica". [Com práticas que] chegavam a ter três, quatro ou mais professores numa mesma sala de aula... era fantástico e eu tenho muita saudade desse médio pra adulto. (Professor Gustavo, entrevista)

O depoimento do professor Gustavo foi reforçado nas considerações dos docentes Antônio, Pedro e Nelson que, ao fazerem referências ao EMA, destacaram a forma como o Projeto era visto dentro de alguns espaços na Instituição: para eles, o EMA era visto por alguns grupos da Escola como um curso menor, devido a seu público alvo, sua forma de acesso (por sorteio) e sua 
proposta pedagógica. Para esses professores, o curso se contrapunha à imagem da rigorosidade no ingresso e na excelência constituída historicamente pela Instituição (Escola Técnica, CEFET/RS, IFSul) ${ }^{4}$. Para os grupos de professores não envolvidos com o curso, o EMA, era entendido como um 'supletivozinho' (conforme considerações do professor Gustavo), em virtude da sua proposta não ter o mesmo formato de avaliação e de desenvolvimento pedagógico. Além disso, tratava-se de um curso com alunos estigmatizados, os quais, desde o ingresso, eram vistos como despreparados e com dificuldades de aprendizagem.

$\mathrm{Na}$ visão dos professores Gustavo e Nelson, o fato de o curso propor uma prática pedagógica diferenciada também não era 'visto com bons olhos', já que isso causava uma ruptura nos padrões culturalmente normatizados na escola. Segundo eles, o EMA trazia uma outra compreensão de espaço e tempo de ensino, a qual quebrava com a ideia da sala de aula como único espaço de ensino e de aprendizagem.

Para o professor Nelson, um dos pontos que mostrava a diferença entre o EMA e os outros cursos, era todos os espaços da escola serem entendidos como ambientes de aprendizagem no EMA, mas, por não haver essa compreensão dentro da Escola, estabelecia-se um choque cultural. Dentro desse paradigma, ele afirmou que "pra eles [referindo-se aos professores dos cursos técnicos] tudo o que é novo aqui [na escola] eles acham que não é dar aula... não é estar em sala de aula [não é ensinar] ... porque, o importante é o aluno estar em sala de aula" (entrevista).

Ao analisar os depoimentos desses docentes, pode-se perceber que o Projeto Especial de Ensino Médio para Adultos enfrentou um processo de resistência dentro da Escola, por ter um formato que rompia com o modelo de excelência e de organização historicamente consagrado na Instituição. Além disso, estabeleceu-se, ali, a partir da criação do EMA, outra forma de ensinar e de aprender que, por seu caráter inovador, pode ter sido repelido pela cultura escolar instituída.

Para Tyack e Cuban (2001) e Viñao Frago (2001), o processo de remodelagem da cultura escolar tem como maior obstáculo as concepções e compreensões normatizadas ao longo do tempo no intramuros escolar. A tentativa

\footnotetext{
4 Nos seus 101 anos de história, a Instituição possuiu distintas denominações, desde Escola de Artes e Officios de Pelotas (1917), passando por Escola Técnica de Pelotas (1942), Centro Federal de Educação Tecnológica de Pelotas - CEFET-RS (1999), até os dias atuais Campus Pelotas do Instituto Federal Sul-riograndense de Educação, Ciências e Tecnologia - IFSul (2008).
} 
de romper com o instituído depara-se com estruturas, regulamentos, modos de ser e de entender a ação docente que, ao longo do tempo, foram consagrados, tornando-se características da "verdadeira escola".

Essa resistência que, no período do EMA, tinha um caráter velado, ganhou outro contorno com a necessidade de se atenderem as exigências do Decreto 5.478/05, que instituiu o PROEJA. Segundo os professores Antônio, Gustavo e Nelson, que participaram do processo de constituição do curso PROEJA, a escolha do curso e a articulação entre as áreas da cultura geral com as áreas técnicas foi um trabalho com vários percalços. Relatam que, quando da promulgação do Decreto e diante da obrigatoriedade de ofertar, a partir do ano de 2006 , o correspondente a $10 \%$ das vagas oferecidas no ano de 2005 , para o Ensino Médio integrado à educação profissional a jovens e adultos, o então Diretor de Ensino da Instituição mostrou-se, inicialmente, entusiasmado com a proposta. Com base nela, convidou todos os coordenadores das áreas técnicas e alguns professores envolvidos com o EMA, para apresentar o Decreto, discutilo e encontrar caminhos para a sua implementação. Após a primeira rodada de conversas, apenas a área de Informática mostrou-se disposta a implementar um curso na modalidade EJA. Em virtude da negativa de todas as outras áreas técnicas, a direção decidiu fazer um sorteio entre elas, e deste, listar três áreas, que seriam obrigadas a cumprir o estabelecido no Decreto.

Após diversas discussões entre os professores da área de cultura geral e da área técnica de Informática, no ano de 2006, o então CEFET/RS Pelotas, dá o primeiro passo no intuito de cumprir a exigência do Decreto (substituído pelo Decreto $n^{\circ} 5.840$, ainda em 2006), e cria o curso Técnico de nível médio em Montagem e Manutenção de Computadores - forma integrada - modalidade EJA, posteriormente denominado Curso Técnico de Nível Médio em Manutenção e Suporte em Informática - modalidade PROEJA. Com a criação do PROEJA, ocorre o início do processo de extinção do EMA e é iniciada nova fase da educação para jovens e adultos no contexto da Instituição.

O projeto do curso de Manutenção e Suporte em Informática foi pensado e concretizado de maneira que as disciplinas de formação de cultura geral e técnica fossem desenvolvidas de forma concomitante ao longo do curso, e não em módulos distintos que se acumulariam no andamento da formação (DOROW et al., 2007).

No entender do professor Nelson, esse aspecto é extremamente relevante para efetivar a integração entre as matérias de cultura geral e as técnicas. Além disso, ao conceber uma matriz curricular em que as disciplinas fossem 
entrelaçadas, o projeto do Curso trazia para discussão outra forma de conceber os cursos integrados, pois rompia com os modelos curriculares em andamento na Instituição, os quais costumavam dividir os cursos distribuindo as matérias de cultura geral no início e as técnicas no final do curso.

No projeto do Curso, a integração curricular entre os saberes da educação geral e da educação profissional está apontada como aspecto que pode garantir a incorporação da dimensão intelectual ao trabalho produtivo, além de possibilitar a formação de trabalhadores capazes de atuar como dirigentes e de cidadãos, "capazes de interagir na sociedade de forma crítica, além de entender e ter conhecimentos técnico-científicos para atuar no processo produtivo" (CEFET, 2007).

Segundo o professor Antônio, a ideia foi aproveitar o grupo de professores do EMA e suas experiências com educação de jovens e adultos (EJA), e aliar a isso a proposta de construção de um outro curso integrado. Ademais, ele afirma que

A gente quis fazer [um projeto/curso] na contramão do que sempre se fez, [...] porque sempre se pega as disciplinas e a carga horária das disciplinas e a partir daí se fazia a proposta. Então nós começamos ao contrário, partindo das características gerais do Ensino Médio e do técnico... primeiro do perfil do [aluno] egresso... depois nós pegamos as características gerais do Ensino Médio e do técnico e a partir dali, olhando para esse perfil, para as características desse curso, nós fizemos as competências gerais do curso, depois um recorte do conhecimento e depois é que as disciplinas começaram a aparecer... e aí sim a gente começou a integrar (professor Antônio, entrevista).

Com esses pressupostos, o projeto do curso de Manutenção e Suporte em Informática tem como perfil do aluno que

Deverá ser um cidadão responsável, empreendedor, investigador e crítico, apto a desempenhar sua profissão no que concerne ao suporte e à manutenção de tecnologias da informação, incluindo hardware e software, por meio de uma formação ética, técnica, criativa e humanística (CEFET, 2008, p. 149).

No entender dos professores Antônio e Nelson, no momento de elaboração das competências curriculares dos alunos para a conclusão do curso, houve uma aproximação entre as áreas, o que permite (ou deveria permitir) o diálogo entre as disciplinas de formação propedêutica e as técnico-profissionais.

Por conseguinte, segundo os professores, a integração curricular no Curso em análise transparece em sua matriz curricular, pois em sua construção houve a preocupação em garantir a oferta de disciplinas de formação propedêutica e técnico-profissional ao longo dos quatro anos. Essa forma concomitante de oferta das disciplinas representa, na visão dos professores Antônio e Nelson, um 
avanço na integração curricular, pois rompe com os parâmetros existentes na Escola, que privilegiavam a oferta de disciplinas de formação geral nos primeiros anos dos cursos e de formação profissionalizante no período final.

Para o professor Nelson, apesar de todas as experiências com práticas pedagógicas integradas, que foram acumuladas com o Ensino Médio para Adultos, a esperada efetivação do curso integrado PROEJA não se concretizou na prática, tendo em vista a dificuldade de diálogo entre os professores das áreas de cultura geral e técnica. Esse distanciamento entre os professores dificultou a integração entre áreas, estabelecendo um forte isolamento entre as disciplinas que compõem o currículo.

Com base em Bernstein (1996), é possível afirmar que esse distanciamento entre as áreas de cultura geral e técnica estabelece uma classificação forte para o currículo. Para o autor, quanto maior o isolamento entre as áreas mais forte é a classificação do currículo e menor é o diálogo entre os conhecimentos das distintas áreas. Assim, apesar de a proposta ter sido pensada na perspectiva de integração curricular entre as áreas, a implementação e o andamento da prática pedagógica foram constituindo um distanciamento entre elas.

Em contrapartida, o mesmo não se observou na relação entre as disciplinas que compunham a formação geral, já que entre os professores dessas disciplinas o diálogo era constante e, por consequência, a classificação fraca, na qual os conteúdos do conjunto de disciplinas de formação geral apresentam um fraco isolamento. Nesse sentido, o professor Nelson salienta que, no EMA, a articulação acontecia entre os professores do Ensino Médio e no PROEJA, a integração deveria envolver também os professores do profissionalizante. Ele enfatiza que

$\mathrm{Na}$ cultura geral a gente propõe um tema gerador... um projeto... oh nós vamos fazer um projeto. Agora no segundo ano eles têm o projeto jornal, todos aderem com maior facilidade, mas no ensino técnico é... uma coisa dolorosa! (Professor Nelson, entrevista).

A cultura presente na escola, para o professor Nelson, tende a consolidar o "endeusamento do ensino técnico", em detrimento da formação propedêutica, o que gera uma distinção e separação entre as áreas e fomenta a supremacia da área técnica sobre a cultura geral. Este processo reforça a classificação do currículo, por evidenciar as fronteiras entre as distintas disciplinas.

Faz pressupor que esse movimento fortalece a dualidade curricular, em que é privilegiada a formação técnico-profissional em detrimento da formação de caráter propedêutico. Conforme Ramos (2005) assim como para Ivo e Hypolito (2011), a dualidade entre as áreas enfraquece a integração curricular entre as áreas 
de formação profissional e propedêutica. Essa dualidade tende a consolidar, na realidade educacional, duas concepções de educação: uma de formação propedêutica, destinada a preparar os sujeitos para o acesso a níveis superiores de ensino; e outra, de caráter técnico-profissional, reservada para a formação de trabalhadores para o mercado.

No entendimento dos professores Nelson e Antônio, a integração curricular no curso de Manutenção e Suporte em Informática pode ser percebida entre as disciplinas da cultura geral. Para Antônio, o diálogo entre as disciplinas propedêuticas vem do EMA, já que boa parte dos projetos interdisciplinares hoje propostos no Curso são resultado de contribuições dos professores que faziam parte do EMA. Segundo Antônio, as atividades formativas asseguradas às terçasfeiras desde o EMA (iniciou-se em 1998) ajudaram na constituição do 'coletivo, do grupo e identidade dos professores', o que, na sua visão, não se reverteu em um trabalho integrado com a área de formação profissional. Dessa forma, ele afirma

Por um lado eu vejo que com o integrado a gente não conseguiu constituir esse
grupo articulado... tu observas [a articulação] entre esse grupo na formação geral...
mas, tu não observas o grupo do PROEJA no sentido assim de olhar o PROEJA
como um curso integrado, que, portanto, tem professores da formação geral e da
formação técnica. (Professor Antônio, entrevista).

O professor Nelson destaca que a integração acontece essencialmente entre as disciplinas propedêuticas e através de projetos de ensino integrados. Segundo ele, esses projetos são decididos e construídos a partir das percepções do grupo de professores acerca das turmas e das necessidades dos alunos. A partir da escolha de um tema nas reuniões de formação, os professores começam a traçar estratégias para o desenvolvimento interdisciplinar de projetos. Assim, segundo Nelson, os projetos nascem de temas geradores significativos para os professores, que serão trabalhados de forma articulada no decorrer do ano letivo.

Apesar de o professor Nelson destacar o papel integrador dos projetos de ensino desenvolvidos com as turmas do PROEJA e fazer referência à relação constituída entre as disciplinas de cultura geral, o que se percebe nos depoimentos dos docentes é que, mesmo entre as disciplinas de cultura geral, essa aproximação ainda é fragilizada. Para os professores Cristiano, Gustavo, Luis, Marcos, Pedro e Felipe, deve-se à falta de tempo para construção de projetos coletivos, ou à falta de diálogo entre os professores que não sabem o que o colega trabalha com as turmas. Acerca disso, salienta o professor Felipe: 
Eu não sei, [por exemplo,] o que o professor de Matemática está trabalhando, nós não estamos integrando... eu não estou... (apesar de estarmos lado a lado nas reuniões...)... Não existe este momento de discutir o que a Química está trabalhando, por exemplo... até agora eu não tive esse momento... talvez eles [professores] tenham feito isso e já esteja organizado... mas, eu não!... estou solto no conteúdo. Eu cheguei e peguei toda a [disciplina] do Ensino Médio... esses são os conteúdos para trabalhar no [curso]... quando eu olhei eu ri! E eu que sou conteudista disse não!... não vou fazer nada disso, porque eu não tenho condições de trabalhar tudo isso que está aqui [em tão pouco tempo]... (entrevista).

Na visão dos professores Rafael e Arturo da área técnica, o distanciamento entre as áreas está ligado à falta de conhecimento dos professores da cultura geral sobre os conteúdos que são trabalhados nas disciplinas de formação profissional. Este aspecto também é ressaltado pelo professor Felipe que, ao analisar a integração curricular, ressalta a falta de conhecimento dos conteúdos que estão sendo estudados pelos alunos nas disciplinas técnicas. No entender desse professor, a integração deve estar presente através de diálogos entre as áreas e de projetos que levem em conta as especificidades de cada campo de conhecimento.

Segundo o professor Felipe, para se estabelecer uma integração curricular "Tínhamos que saber o que eles [alunos] vão estudar" (trecho de entrevista), para que fosse possível estabelecer uma conexão entre os saberes ensinados nas disciplinas.

No entender do professor Rafael, que trabalha com a disciplina de hardware, o distanciamento entre a formação geral e profissional no PROEJA ficou ressaltado no momento em que os professores das disciplinas técnicas perceberam as dificuldades que os alunos, jovens e adultos, tinham para lidar com as tecnologias e suas linguagens. Ao se depararem com alunos que temiam a máquina, os professores da parte profissional não obtiveram respaldo dos professores de formação geral para articular o trabalho com essas ferramentas tão desconhecidas para os estudantes. Para esse professor, a responsabilidade precisava ser dividida ou ser abraçada e trabalhada por todos e não apenas recair sobre os professores da área técnica, visto que um trabalho integrado significa "integrar tudo", desde os aspectos mais cotidianos até as atividades mais complexas de sala de aula.

Conforme Bernstein (1996) e Ramos (2005), a forte classificação entre as áreas de conhecimento estabelece uma fronteira, que dificulta a integração curricular. Em uma proposta integrada há uma articulação entre as disciplinas e áreas antes isoladas, de tal modo que se constata o "abrandamento dos enquadramentos e das classificações do conhecimento escolar" permitindo 
aproximações entre professores e alunos, e a articulação dos saberes escolares com os saberes cotidianos dos alunos, diluindo a "visão hierárquica e dogmática do conhecimento" (RAMOS, 2005, p. 114).

Para o professor Nick, a soma de muitos fatores fez com que o curso técnico integrado ao Ensino Médio na modalidade EJA assumisse características de um curso concomitante, já que a formação de cultura geral e a profissionalizante pareciam acontecer de forma paralela. Segundo ele, apesar do projeto pedagógico do curso ter sido construído com base em uma proposta de integração a distância entre as áreas de formação, não permitiu a consolidação de práticas pedagógicas integradas. A este respeito ressalta o professor que: “Temos um Curso integrado, que na prática tem um formato concomitante... são dois cursos ao mesmo tempo... Ensino Médio e Técnico na área de Informática... mas isto, não é um privilégio apenas do PROEJA" (Diário de Campo, junho de 2010).

O que se percebe, no depoimento desse professor, é a existência de um distanciamento entre o que foi concebido teoricamente como currículo integrado e as práticas de ensinar e aprender que ocorrem no cotidiano escolar, as quais não conseguem aproximar o Ensino Médio e a educação profissional.

Outro aspecto que se percebe é que o "endeusamento do ensino técnico" faz parte da cultura escolar da Instituição e está impregnado em toda a vida escolar, que transita no IFSul, considerando alunos, professores, normas e concepções.

Segundo Viñao Frago (2006), a cultura escolar é um “conjunto de aspectos institucionalizados", que abrange práticas e condutas, modos de vida, hábitos e ritos cotidianos do fazer escolar, objetos materiais (função, uso, distribuição no espaço, materialidade física, simbólica, introdução, transformação, transposição ou superação, etc.) e modos de pensar. É também um conjunto de significados e de ideias compartilhadas.

Com base em Viñao Frago (2001, 2006), percebe-se que as políticas, principalmente aquelas que pretendam mexer no cotidiano escolar, têm que levar em conta as dinâmicas deste cotidiano e construir as mudanças pretendidas, tendo como pressuposto uma interlocução com os sujeitos que fazem esta cultura, pois aparenta não acontecer na Instituição em estudo.

Para Viñao Frago (2001, 2006), o caráter essencialmente histórico da cultura escolar e "a-histórico" das reformas educacionais, que desconhecem a existência da cultura própria da instituição e ignoram o "Conjunto de tradições e regularidades institucionais" ${ }^{\prime}$ sedimentadas ao longo do tempo. Para ele, esse fato pode explicar a superficialidade das tentativas de câmbio propostas pelos governos, 
que, em sua maioria, limitam-se a "Roçar a epiderme da atividade educativa sem modificar, apesar do que às vezes se manifesta, a escola real, a realidade cotidiana de tal atividade e a vida dos estabelecimentos" (VIÑAO FRAGO, 2001, p. 30).

\section{CONSIDERAÇÕES FINAIS}

No estudo, evidenciou-se que o PROEJA, ao possibilitar a integração de três áreas - o ensino básico, a educação profissional de nível técnico e a educação de jovens e adultos, caracteriza-se como uma iniciativa inovadora para o contexto educacional. Essa integração é alicerçada em um projeto educativo que rompe com a ideia de divisão em segmentos e sobreposições, as quais tão pouco revelam das possibilidades de ver mais completamente a realidade. Assim, o Programa nasceu com o objetivo de proporcionar, aos alunos jovens e adultos trabalhadores, oportunidades de escolarização, aliando a Educação Básica à Educação Profissional, rompendo, dessa forma, com políticas que se restringem “à questão do analfabetismo, sem articulação com a educação básica como um todo, nem com a formação para o trabalho, nem com as especificidades setoriais [...]" (BRASIL, 2007, p. 18).

O PROEJA trouxe em seu texto uma nova proposta pedagógica e foi um grande desafio para a Instituição campo de pesquisa e para seus professores, em virtude da proposta de integração curricular e de abertura da escola para alunos jovens e adultos já algum tempo afastados dos bancos escolares.

Além disso, por ser um programa em implementação, a todo instante surgiam novas discussões acerca dessa modalidade de ensino nas diversas esferas que permeiam a escola e o sistema educacional. Isso porque as experiências que vinculam elevação de escolaridade e trabalho voltadas para jovens e adultos trabalhadores, com especial destaque para o PROEJA, vêm produzindo um conhecimento inédito, do qual muito pode beneficia-se a escola em seu conjunto e a EJA de forma privilegiada, já que historicamente têm sido implementadas propostas pedagógicas que desconsideram os saberes produzidos pelos sujeitos jovens e adultos.

Como é amplamente aceito, o currículo é o espaço central em que se definem as ações pedagógicas; é a arena em que se travam lutas por diferentes concepções e paradigmas, em que certas vozes são ouvidas e outras não; é a arena educativa privilegiada de busca por hegemonia. Nesse sentido, o currículo desempenha papel fundamental no programa PROEJA e suas concepções e princípios básicos encaminham e propõem um modelo de currículo integrado. 
O estudo permitiu identificar entre os professores diferentes percepções da efetivação do currículo integrado no curso de Manutenção e Suporte em Informática. Apesar disso, na elaboração do projeto do curso, a proposta de currículo integrado foi entendida a partir do modelo curricular do Curso, no qual as disciplinas gerais e técnicas deveriam ocorrer concomitantemente. Contudo, quando posto em prática, o currículo não avançou como era esperado e, portanto, pode-se admitir limitações na articulação entre a formação técnica e a formação geral.

A partir desta análise ficaram evidentes distanciamentos entre as concepções e princípios norteadores do Documento Base do Programa e as propostas curriculares do Curso. Tal fenômeno reforça a concepção de que, no contexto da prática, as políticas são interpretadas, recontextualizadas e assumem novas características, pois os profissionais que atuam no contexto da prática não enfrentam os textos políticos como meros receptores, mas, sim, como sujeitos que estão envoltos pela cultura escolar e por possuírem experiências, valores e perspectivas diversas.

Assim, é possível afirmar que o contexto escolar é constituído por grupos e concepções distintos, que hibridizam e dão forma à cultura escolar. Nesse caso, a cultura escolar forma-se dos conflitos estabelecidos entre as diferentes percepções da escola, que em um campo de disputas vão configurando a cultura escolar a partir da articulação entre diversos modelos. Esse movimento produz uma cultura escolar hibridizada, que aproxima o atual e o antigo ou o tradicional e o inovador.

Foi possível, assim, perceber na escola a presença de embates permanentes entre concepções e práticas diferentes de ensino. No caso em análise, ficou evidente que o texto produzido pela Instituição reflete um discurso pedagógico que se mostra em contraposição ao discurso do mercado produtivo. Apesar disso, há uma aparente zona de conflito entre os distintos discursos presentes na Instituição, que se estabelecem entre os contextos de produção do texto institucional, de recontextualização e da prática.

Logo, os textos institucionais ao serem recontextualizados sofrem com a influência da cultura hegemônica, que tem o mercado de trabalho como foco primordial da formação. Essa influência tem reflexo no contexto da prática, onde se identifica a aparente presença de concepções e práticas pedagógicas que enfatizam a formação voltada para o mercado. Desse modo, a cultura escolar do IFSul é forjada a partir de específicos discursos, que permeiam esse campo de tensões e transitam por extremos. 


\section{REFERÊNCIAS}

ALVES, M. F.; CASTRO, M. D. R. de. A constituição da educação profissional na modalidade de educação de jovens e adultos - as experiências do PROEJA em Goiás. $2^{\circ}$ Simpósio Brasileiro e $2^{\circ}$ Congresso Interamericano de Política e Administração da Educação, Anais... Porto Alegre, RS, 2007.

BERNSTEIN, B. A estruturação do discurso pedagógico: Classe, Códigos e Controle. Petrópolis: Vozes, 1996.

BRASIL. Ministério da Educação/Secretaria de Educação Tecnológica e Profissional. Programa nacional de integração da educação profissional com a educação básica na modalidade de educação de jovens e adultos - Documento Base, Brasília, 2007. Disponível em: < http://portal.mec.gov.br/ setec/arquivos/pdf2/proeja_medio.pdf> Acesso em: 29 jul. 2018.

BRASIL. Decreto $\mathbf{n}^{\mathbf{0}} \mathbf{5 . 8 4 0}$, de 13 de julho de 2006. Institui, no âmbito federal, o Programa Nacional de Integração da Educação Profissional com a Educação Básica na Modalidade de Educação de Jovens e Adultos - PROEJA, e dá outras providências. Disponível em: < http://www.planalto.gov.br/ccivil_03/_ato20042006/2006/Decreto/D5840.htm> Acesso em: 29 jul. 2018.

BRASIL. Decreto $\mathbf{n}^{\mathbf{0}} \mathbf{5 . 4 7 8}$, de 24 de junho de 2005. Institui, no âmbito das instituições federais de educação tecnológica, o Programa de Integração da Educação Profissional ao Ensino Médio na Modalidade de Educação de Jovens e Adultos - PROEJA. Disponível em: <http://portal.mec.gov.br/setec/arquivos/ pdf/dec5840_13jul06.pdf> Acesso em: 29 jul. 2018.

BRASIL. Decreto $\mathbf{n}^{\mathbf{0}} \mathbf{2 . 2 0 8}$, de 17 de abril de 1997. Regulamenta o $\int 2^{\circ}$ do art. 36 e os arts. 39 a 42 da Lei no 9.394 , de 20 de dezembro de 1996, que estabelece as diretrizes e bases da educação nacional. Disponível em: $<$ http:/ /www.planalto. gov.br/ccivil_03/decreto/D2208.htm> Acesso em: 29 jul. 2018.

CEFET - Centro Federal de Educação Tecnológica de Pelotas. Projeto político pedagógico: uma construção participativa. Pelotas: CEFET/RS, 2008.

CEFET - Centro Federal de Educação Tecnológica de Pelotas. Projeto do curso técnico de nível médio em Manutenção e Suporte em Informática - forma integrada - modalidade EJA. Pelotas, 2007. Não publicado. 
CEFET - Centro Federal de Educação Tecnológica de Pelotas. Relatório de gestão/2004. Pelotas: CEFET/RS, 2004.

CEFET- Centro Federal de Educação Tecnológica de Pelotas. Projeto Especial de Ensino Médio para Adultos (EMA). Pelotas, 1999. Não publicado.

DOROW, C. et al. O PROEJA: a construção de uma formação continuada. In: SANTOS, S. V. dos. et al. (orgs.). Reflexões sobre a prática e a teoria em PROEJA: produções da especialização PROEJA/RS. 2007. p. 32-43.

IVO, A. A.; HYPOLITO, Á. M. Currículo e educação profissional: uma proposta curricular para o PROEJA em análise. Cadernos de Educação (UFPel), v. 20, p. 201-233, 2011.

MAFRA, L. de A. A sociologia dos estabelecimentos escolares: passado e presente de um campo de pesquisa em re-construção. In: ZAGO, N. et al. (Orgs.). Itinerários de pesquisa: perspectivas qualitativas em sociologia da educação. Rio de Janeiro: DP\&A, 2003. p. 109-136.

NÓVOA, A. Para uma análise das instituições escolares. In: NÓVOA, A. (org.). As organizações escolares em análise. Lisboa, PT: Dom Quixote, 1995. p. 13-43.

RAMOS, M. N. Possibilidades e desafios na organização do currículo integrado. In: FRIGOTTO, G.; CIAVATTA, M.; RAMOS, M. N. Ensino Médio integrado: concepções e contradições. São Paulo: Cortez, 2005. p. 106-127.

TEIXEIRA, L. H. G. Políticas públicas de educação e mudança nas escolas: um estudo da cultura escolar. In: OLIVEIRA, D. A.; DUARTE, M. R. T. (Orgs.). Política e trabalho na escola: administração dos sistemas públicos de educação básica. 3. ed. Belo Horizonte, MG: Autêntica, 2003. p. 177-190.

TYACK, D.; CUBAN, L. En busca de la utopía: un siglo de reformas de las escuelas públicas. Tradução: Mónica Utrilla. México: Fondo de cultura económica, 2001.

VIÑAO FRAGO, A. Sistemas educativos, culturas escolares y reformas: continuidades y câmbios. $2^{\mathrm{a}}$ ed. Madrid: Morata, 2006. 
VIÑAO FRAGO, A. ¿Fracasan las reformas educativas? La respuesta de un historiador. In: SOCIEDADE BRASILEIRA DE HISTÓRIA DA EDUCAÇÃO (Org.). Educação no Brasil: história e historiografia. Campinas, SP: Autores Associados, 2001. p. 21-52.

VALDINEI MARCOLLA é licenciado em Pedagogia (Unioeste), Mestre em Educação e Doutor em Educação (UFPel); e líder do Grupo de Pesquisa Educação, Sociedade e Linguagens no Instituto Federal Catarinense - IFC. Atua como professor do curso de Pedagogia do IFC - Campus Videira. E-mail: valdinei.marcolla@gmail.com

Recebido em setembro de 2018 Aprovado em novembro de 2018 